\title{
Functional Results of Transverse Extended Incision in Cervical Neck Dissection
}

\author{
Carlos Miguel Chiesa-Estomba ${ }^{1}$ Jon Alexander Sistiaga-Suarez ${ }^{1} \quad$ Izaskun Thomas-Arrizabalaga ${ }^{1}$ \\ Jose Angel González-García ${ }^{1} \quad$ Ekhiñe Larruscain $^{1} \quad$ Xabier Altuna $^{1}$ \\ 1 Department of Otorhinolaryngology - Head and Neck Surgery, \\ Hospital Universitario Donostia, País Vasco, Spain \\ Int Arch Otorhinolaryngol 2021;25(1):e27-e34. \\ Address for correspondence Carlos Chiesa, MD, MSc, Department of \\ Otorhinolaryngology - Head and Neck Surgery, Hospital Universitario \\ Donostia, Calle Virgen del Carmen, \#28, 5to C. CP. 20012, \\ San Sebastian, Donosti, País Vasco, Spain \\ (e-mail: chiesaestomba86@gmail.com).
}

\begin{abstract}
Keywords

- cervical neck dissection

- postoperative complication

- scar

Introduction Multiple incisions have been described for the surgical approach of cervical neck nodes. All of these descriptions are associated with better or worse exposure of the surgical field as well as with different functional and aesthetic results, which are not always satisfactory.

Objective Compare the transverse cervical incision with the classic incision in $\mathrm{J}$ or $\mathrm{U}$. Methods This is a retrospective study of 47 patients who required cervical neck dissection between June 15, 2016 and June 15, 2017.A transversal incision was made in these surgeries, and their results were then compared with those of a group of 57 patients treated between January 1, 2010 and January 1, 2012, in whose cases an incision in J or $\mathrm{U}$ was made.

Results Regarding the incision type, complications were present in $4(8.5 \%)$ cases in the transversal incision group, and in 7 (12.2\%) patients of the group of traditional incisions in J or $U$, without statistical differences $(p=0.078)$. The only variables associated with complications of healing in the two groups was body mass index $(\mathrm{BMI})<18.5$. The patients showed subjective satisfaction with the aesthetic result of the transverse incision, with an average of 7.51 vs 6.20 in the J or $U$ incision.

Conclusion The transverse incision represents a safe, aesthetic, and oncologically adequate option, associated with a lower cicatricial retraction rate, without significant complication rate and allowing adequate exposure of the surgical field, similar to the obtained with the classic incision in J or U.
\end{abstract}

\section{Introduction}

Since the original description of radical neck dissection proposed by Crile in $1906,{ }^{1}$ which included the resection of the sternocleidomastoid (SCM) muscle, the jugular vein $(\mathrm{YV})$, and the spinal nerve $(\mathrm{SN})$, to the evolution of the technique to the functional neck dissection following the fascial plane described by Suarez ${ }^{2}$ and popularized by Gavilan $^{3}$ and Bocca, ${ }^{4}$ passing through the classification of selective and modified radical neck dissection proposed by the American Academy of Otolaryngology-Head and Neck Surgery (AAO-HNS), ${ }^{5}$ multiple cervical incisions have been described with the purpose of carrying out this type of surgical intervention. received

December 11, 2018

accepted

DOI https://doi.org/

10.1055/s-0039-3402439.

ISSN 1809-9777. 
Kocher, in $1880,{ }^{6}$ and Kuettner, in $1898,{ }^{7}$ would describe the first incisions for neck node dissection. In 1951, Martin would report the incision in double $\mathrm{Y}^{8}$ and MacFee, in 1960, would describe the double transverse incision. ${ }^{9}$ Meanwhile, in Europe, the bi-mastoid incision, related by Gluck-Sorensen and Tapia, as well as the J incision, described by Paul-André, became more popular. ${ }^{10}$ In 1957, Attie described the use of transverse cervical incision as the technique of choice when performing radical neck dissection ${ }^{11}$ and since 1979 , thanks to the studies performed by Becker, this incision became popular in the United States. ${ }^{12}$

Among all the incisions, it will be essential to follow some criteria that help us choose the best one. These criteria can be grouped as follows: 1) Adequate exposure of the surgical field, 2) Adequate blood flow to the apron flaps, 3) Adequate relationship of the incision to the YV and the carotid artery (CA), 4) Easy conversion or adequate to access to the resection of a primary tumor, 5) Useful to create the tracheal stoma 6) Compatible with any reconstructive effort and 7) Aesthetically acceptable. ${ }^{6}$

In our center, the extended cervical (horizontal) transverse incision was introduced in 2012, and it began to be systematically performed in any cervical neck dissection since 2014, modifying and expanding the incision when the primary tumor resection was required. Once the procedure is standardized, we can present our results below.

\section{Materials and Methods}

A retrospective analysis was performed with the approval of the ethics committee of our institution. Forty-seven patients diagnosed with malignant head $\&$ neck tumors between June of 2016 and June of 2017 who required a primary surgical treatment or rescue, accompanied by a selective, radical modified or radical neck dissection with at least 6 months of postoperative follow-up in which an extended transverse incision was used were included as a study group. All tumors were classified according to the criteria of the Union Internationale Contre le Cancer (UICC) and the American Joint Committee on Cancer (AJCC-7th edition). All patients requiring a surgical
A
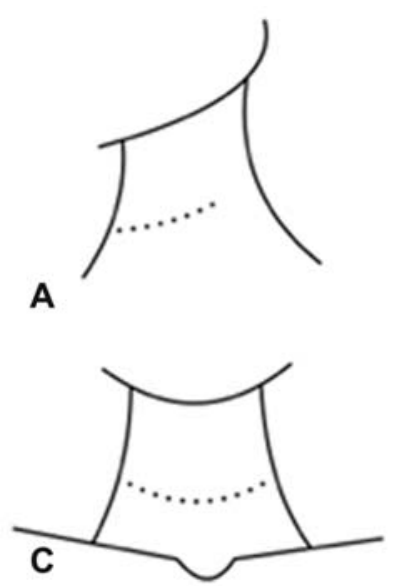

B
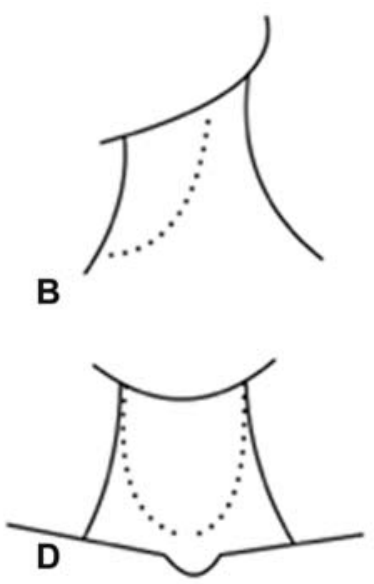

Fig. 1 A) Unilateral transverse - Horizontal incision B) Incision in J of Paul-Andre. C) Bilateral transverse - Horizontal incision D) Bimastoid incision in $\mathrm{U}$ of Gluck-Sorensen-Tapia. reintervention or cutaneous reconstruction were excluded. As a control group, we included a historical retrospective cohort of those patients who required surgical treatment for similar indications, between January of 2010 and January of 2012, in which the incision used was in $\mathrm{J}$ (Paul-Andre) or classic $\mathrm{U}$ (Gluck-Sorensen-Tapia). (- Fig. 1).

Patients previously treated by radiotherapy (RT) or chemotherapy/radiotherapy (CT/RT) and who were considered candidates for salvage surgery due to tumor recurrence received standard RT as organ preservation treatment at doses of $2 \mathrm{~Gy}$ daily, for a total dose of between 64 and $70 \mathrm{~Gy}$. The patients who required $\mathrm{CT}$ were given a regimen of cisplatin ( $100 \mathrm{mg} / \mathrm{m} 2$ ) every 3 weeks. In the postoperative setting, some patients precise postoperative radiation therapy treatment for a total dose of between 66 and 70 Gy for those with high-risk factors, and 50 and 54 for those with low-risk factors.

Regarding the surgical technique, a transverse (horizontal) incision was performed at the level of the midline of the thyroid cartilage when a selective supraomohyoid or cervical jugular dissection was involved. When the neck dissection includes level $\mathrm{V}$, the incision will be drawn at the level of the cricothyroid membrane. The extension of the incision will depend on the type of neck dissection to be performed. In case of unilateral neck dissection, the incision will start from the posterior edge of the SCM muscle and will exceed $2 \mathrm{~cm}$ of the midline in the contralateral direction. If it is necessary to include the level $\mathrm{V}$, the incision may extend up to $3 \mathrm{~cm}$ behind the posterior edge of the ESCM. In the case of bilateral cervical neck dissection, the incision would extend on both sides of the neck to the posterior border of the SCM. The upper flap will be elevated until the lower border of the jaw is palpated, and the lower flap is then raised to the level of the clavicle. If a first intraoral approach is necessary, the incision will rise parallel to the tassel of the chin, and we will have to incise the midline at the level of the lip. If it is necessary to include the parotid in the neck dissection, we will start by making a modified Blair incision and continue our incision at the level of a horizontal fold of the neck. Once elevated, both flaps are fixed with Lone Star surgical elastic bands (Lone Star Surgical, Laredo, TX, USA) (- Fig. 1).

Due to the absence of specific scales validated regarding aesthetic results in cervical incisions after oncological surgery, a visual analogue scale (VAS) was presented to each patient 6 months after surgery questioning about the aesthetic results and life quality, and the surgeons were consulted regarding the wound results. Great auricular nerve damage was evaluated subjectively according to the patient's sensation the day after surgery in the ward round.

The statistical analysis was performed using the JASP Version 0.8.5.1 computer software (University of Amsterdam, Amsterdam, Netherlands). The Kolmogorov-Smirnov was used to assess the normal distribution. The quantitative variables within the study are expressed as a mean \pm standard deviation; the results are expressed as both total and percentage. The Chisquared test and the Fischer test were used in the univariate analysis. The comparison concerning partial or total necrosis of the flap, aesthetic results and quality of life between both groups was performed using the Student $t$-test for paired data and the $p$-value $<0.05$ was considered significant. 


\section{Results}

A total of 104 patients were included. Forty-seven patients in the study group, 38 men $(80.9 \%)$ and 9 women (19.1\%) with an average age of 62.79 years ( \pm 12.19 ; $\min : 35 / \max : 84)$. Fifty-seven patients were included in the control group, 35 men (61.4\%) and 22 women (38.6\%) with an average age of 62.02 years ( \pm 11.28 ; min: 30/max: 82 ). The clinical and demographic data can be seen in -Table 1.

Sixty-nine cervical neck dissections were performed in the study group, and 70 in the control group. The type of surgery can be reviewed in - Table $\mathbf{2}$, the type of cervical neck dissection performed and the frequency of these can be reviewed in - Table 3 . It was possible to isolate an average of $18 \pm 7$ (min: 11/max: 39 ) lymph nodes in the study group, while in the historical control group an average of $16 \pm 5$ lymph nodes were isolated (min: 6/max: 29). Regarding complications related to the incision or the elevation of both flaps, we did not find significant differences regarding complications between both $(p=0.078)$ ( - Table 4$)$. In the univariate analysis, factors that could be associated with an alteration in healing were included, with malnutrition being the only factor related to flap damage $(p=0.001)$. Regarding the aesthetic result, the patients showed subjective compliance according to VAS, with a mean of 7.25 in the study group and 6,20 in the historical cohort $(p=0.002)$. According to their quality of life, the patients in the study group report a mean of 6.91 versus a 7.71 in the historical cohort $(p=0.721)$. The aesthetic assessment of the surgeon regarding the wound results in the follow-up was favorable in $65.7 \%$ of the cases in the study group and $60 \%$ of cases in the historical cohort (-Table 5).

Table 1 Demographic data and statistical comparison of the variables associated with failure during the post-surgical healing

\begin{tabular}{|c|c|c|c|}
\hline Variable & $\begin{array}{l}\text { Transverse } \\
\text { incision - N (\%) }\end{array}$ & $\begin{array}{l}\text { J or } U \\
\text { incision - N (\%) }\end{array}$ & $P($ UA) \\
\hline \multicolumn{4}{|l|}{ Sex } \\
\hline Men & $38(80.9)$ & $35(61.4)$ & \\
\hline Women & $9(19.1)$ & $22(38.6)$ & \\
\hline Age & $\begin{array}{l}62.79 \pm 12.1 \\
\text { (Min: 25/Max: } 84 \text { ) }\end{array}$ & $\begin{array}{l}62.02 \pm 11.28 \\
\text { (Min: 30/Max: 82) }\end{array}$ & 0.984 \\
\hline \multicolumn{4}{|l|}{ ASA } \\
\hline 1 & $0(0)$ & $1(1.8)$ & \multirow[t]{4}{*}{0.830} \\
\hline 2 & $24(51.1)$ & 25 (43.9) & \\
\hline 3 & $22(46.8)$ & $31(54.4)$ & \\
\hline 4 & $1(2.1)$ & $0(0)$ & \\
\hline \multicolumn{4}{|l|}{ COPD } \\
\hline Yes & $8(17)$ & $10(17.5)$ & \multirow[t]{2}{*}{0.736} \\
\hline No & $39(83)$ & $47(82.5)$ & \\
\hline \multicolumn{4}{|l|}{ Cardiopathy } \\
\hline Yes & $14(29.8)$ & $17(29.8)$ & \multirow[t]{2}{*}{0.602} \\
\hline No & $33(70.2)$ & $40(70.2)$ & \\
\hline \multicolumn{4}{|l|}{ Smoker } \\
\hline Yes & $33(70.2)$ & $19(33.3)$ & \multirow[t]{4}{*}{0.249} \\
\hline No & $8(17)$ & $8(14)$ & \\
\hline Ex & $6(12.8)$ & $30(52.6)$ & \\
\hline $\begin{array}{l}\text { Mean number of } \\
\text { packages per year }\end{array}$ & $\begin{array}{l}38.5 \pm 28.88 \\
\text { (Min 10/Max: 100) }\end{array}$ & $\begin{array}{l}26.58 \pm 16.7 \\
\text { (Min: 12/Max: 60) }\end{array}$ & \\
\hline \multicolumn{4}{|l|}{ Alcohol } \\
\hline Yes (> 70 g/day) & $36(76.6)$ & $44(77.19)$ & \multirow[t]{2}{*}{0.605} \\
\hline No (< $70 \mathrm{~g} /$ day) & $11(23.4)$ & $13(22,8)$ & \\
\hline \multicolumn{4}{|l|}{$\mathrm{BMI}<18.5$} \\
\hline Yes & $8(17)$ & $4(7)$ & \multirow[t]{2}{*}{0.001} \\
\hline No & $39(83)$ & $53(93)$ & \\
\hline
\end{tabular}


Table 1 (Continued)

\begin{tabular}{|c|c|c|c|}
\hline Variable & $\begin{array}{l}\text { Transverse } \\
\text { incision - N (\%) }\end{array}$ & $\begin{array}{l}\text { J or U } \\
\text { incision - N (\%) }\end{array}$ & $P(\mathrm{UA})$ \\
\hline \multicolumn{4}{|l|}{ Obesity } \\
\hline Yes & $14(29.8)$ & $2(3.5)$ & \multirow[t]{2}{*}{0.190} \\
\hline No & $33(70.2)$ & $55(96.5)$ & \\
\hline \multicolumn{4}{|l|}{ Hypertension (HTA) } \\
\hline Yes & $20(42.6)$ & $21(36.8)$ & \multirow[t]{2}{*}{0.700} \\
\hline No & $27(57.4)$ & $36(63.2)$ & \\
\hline \multicolumn{4}{|l|}{ Diabetes Mellitus (DM) } \\
\hline Yes (non-insulin dependent) & $11(23.4)$ & $11(19.3)$ & \multirow[t]{2}{*}{0.100} \\
\hline No & $36(76.6)$ & $46(80.7)$ & \\
\hline Tx & $0(0)$ & $7(12.3)$ & \multirow[t]{5}{*}{0.018} \\
\hline T1 & $5(10.6)$ & $7(12.3)$ & \\
\hline $\mathrm{T} 2$ & $17(36.2)$ & $24(42.1)$ & \\
\hline T3 & $7(14.9)$ & $9(15.8)$ & \\
\hline $\mathrm{T} 4$ & $18(38.3)$ & $10(17.54)$ & \\
\hline NO & $24(51.1)$ & $18(31.6)$ & \multirow[t]{6}{*}{0.365} \\
\hline N1 & $11(23.4)$ & $13(22.8)$ & \\
\hline $\mathrm{N} 2 \mathrm{a}$ & $3(6.3)$ & $14(24.6)$ & \\
\hline $\mathrm{N} 2 \mathrm{~b}$ & $8(17)$ & $7(12.3)$ & \\
\hline $\mathrm{N} 2 \mathrm{c}$ & $1(2.1)$ & $3(5.3)$ & \\
\hline N3 & $0(0)$ & $2(3.5)$ & \\
\hline M0 & $47(100)$ & $57(100)$ & \\
\hline M1 & $0(0)$ & 0 & \\
\hline Histology & & & 0.771 \\
\hline - Squamous cell carcinoma & $44(94.6)$ & $51(89.5)$ & \\
\hline - Adenocarcinoma & $3(5.4)$ & $4(7.1)$ & \\
\hline - Melanoma & $0(0)$ & $1(1.8)$ & \\
\hline - Undifferentiated nasopharyngeal carcinoma & $0(0)$ & $1(1.8)$ & \\
\hline $\mathrm{RT}$ or previous $\mathrm{CT} / \mathrm{RT}$ & $6(12.7)$ & $14(24.6)$ & 0.079 \\
\hline Parcial o total flap damage & $4(8.5)$ & $7(12.2)$ & 0.078 \\
\hline
\end{tabular}

Abbreviations: BMI, body mass index; COPD, chronic obstructive pulmonary disease; CT, chemotherapy; DM, ; HTDA, ; RT, radiotherapy. $P(U A)$, univariate analysis.

The statistical result for partial or total damage of the flap corresponds to the comparison between both groups.

\section{Discussion}

Before performing a cervical neck dissection, it is essential to know the vascularization patterns of the skin in the neck. Kambic and Sirca, in 1967, showed that the lateral cervical cutaneous vascularization was directed vertically, receiving blood supply from the descending perforating branches of the facial, submental, occipital, posterior auricular and external carotid arteries, as well as from the ascending branches of the transverse cervical and suprascapular artery. Also, the platismocutaneous branches of the superior thyroid artery irrigate the skin of the anterior region in the neck. ${ }^{13}$ In 1985, Rabson et al, in a study performed on cadavers, describe the presence of arterial perforators of the platysma muscle to the skin of the neck as well as the anastomosis between them, which will guarantee arterial blood supply at this level during the elevation of the apron flap. ${ }^{14}$

Despite the different incisions described in the literature, it is evident that most of them do not respect the natural skin tension lines originally described by Langer, ${ }^{15}$ with the increased risk of contractures at the level of the scar or the appearance of keloids or hypertrophic scars. The alteration of these tension lines secondary to cicatricial retraction will condition the range of cervical mobility, ${ }^{16}$ causing pain, in some cases, which may be disabling, directly affecting the physical activity and quality of life of the patient. 
Table 2 Type of surgery performed

\begin{tabular}{|c|c|c|}
\hline Type of surgery & $\begin{array}{l}\text { Transverse } \\
\text { incision - N (\%) }\end{array}$ & $\begin{array}{l}\text { J or U } \\
\text { incision - N (\%) }\end{array}$ \\
\hline $\mathrm{TL}+\mathrm{CND}$ & $12(26.5)$ & $12(21.1)$ \\
\hline TLM + CND & $5(10.6)$ & $7(12.28)$ \\
\hline THPLM + CND & $5(10.6)$ & $3(5.26)$ \\
\hline Glossectomy + CND & $5(10.6)$ & $5(8.8)$ \\
\hline $\begin{array}{l}\text { Transoral } \\
\text { oropharyngectomy } \\
+ \text { CND }\end{array}$ & $9(19.1)$ & $2(3.5)$ \\
\hline $\mathrm{FM}+\mathrm{CND}$ & $1(2.1)$ & $0(0)$ \\
\hline RND & $4(8.5)$ & $5(8.8)$ \\
\hline MND & $0(0)$ & $10(17.5)$ \\
\hline Parotidectomy + CND & $3(6.4)$ & $4(7.32)$ \\
\hline Submaxilectomy + CND & $1(2.1)$ & $1(1.8)$ \\
\hline Maxilectomy + CND & $1(2.1)$ & $0(0)$ \\
\hline Cheek Mucosa + CND & $1(2.1)$ & $0(0)$ \\
\hline \multicolumn{3}{|l|}{ Regional flap } \\
\hline - Pec major flap & $4(8.5)$ & $3(5.3)$ \\
\hline $\begin{array}{l}\text { - Supraclavicular } \\
\text { island flap }\end{array}$ & $2(4.25)$ & $0(0)$ \\
\hline - FAMM & $2(4.25)$ & $0(0)$ \\
\hline \multicolumn{3}{|l|}{ Free Flap } \\
\hline - Radial forearm flap & $1(2.1)$ & $2(3.5)$ \\
\hline - Fibula & $1(2.1)$ & $0(0)$ \\
\hline
\end{tabular}

Abbreviations: CND, cervical neck dissection; FAMM, facial artery musculo-mucosal flap; FM, floor of the mouth; MND, modified neck dissection; RND, radical neck dissection; THP, transoral hypopharyngeal Co2 laser microsurgery; TL, total laryngectomy; TLM, transoral Co2 laser microsurgery - glottis and supraglottis are included.

Since the inclusion of RT in the treatment schemes of head and neck tumors, there has been an increased risk of healing failure. From the initial works presented by Ellis ${ }^{17}$ and Stell, ${ }^{18}$ who described failures in the wound primary closure of $79 \%$ and $55 \%$ of the cases, respectively, several series report similar results, with the posterior flap and the trifurcation area being the most frequent sites of necrosis and dehiscence, leading to an increased risk of carotid exposure and blowout. ${ }^{19}$ Acar et al, ${ }^{20}$ in a series in which included 320 patients who had undergone a J incision, described a dehiscence rate of $12.6 \%$, a rate of apron flap necrosis of $3.3 \%$, and contracture at the
Table 4 Postsurgical complications

\begin{tabular}{|l|l|l|}
\hline Type & $\begin{array}{l}\text { Transverse } \\
\text { incision } \\
\text { number (\%) }\end{array}$ & $\begin{array}{l}\text { J or U incision } \\
\text { number (\%) }\end{array}$ \\
\hline Bleeding & $7(14.9)$ & $2(3.6)$ \\
\hline Marginal paresis & $4(8.51)$ & $2(3.6)$ \\
\hline Surgical flap dehiscence & $3(6.38)$ & $5(8.77)$ \\
\hline $\begin{array}{l}\text { Tracheal stoma suture } \\
\text { dehiscence }\end{array}$ & $1(2.1)$ & $1(1.8)$ \\
\hline Lymphatic leak & $2(4.2)$ & $2(3.6)$ \\
\hline Seroma & $1(2.1)$ & $1(1.8)$ \\
\hline Partial flap necrosis & $0(0)$ & $1(1.8)$ \\
\hline Superior flap lymphedema & $6(12.7)$ & No data available \\
\hline GAN lesion & $5(10.6)$ & No data available \\
\hline
\end{tabular}

Abbreviation: GAN, great auricular nerve.

Table 5 Quality of life of patients and subjective perception of the surgical wound

\begin{tabular}{|c|c|c|c|}
\hline Variable & $\begin{array}{l}\text { Transverse } \\
\text { incision }\end{array}$ & $\begin{array}{l}\text { J or U } \\
\text { incision }\end{array}$ & $p$ \\
\hline $\begin{array}{l}\text { Aesthetic perception } \\
\text { of the patient (VAS 0-10) }\end{array}$ & 7.25 & 6.20 & 0.002 \\
\hline Quality of life (VAS 0-10) & 6.91 & 6.71 & 0.721 \\
\hline \multicolumn{4}{|l|}{ Surgeon's assessment } \\
\hline $\begin{array}{l}\text { - Wound with } \\
\text { correct healing }\end{array}$ & $65.7 \%$ & $60 \%$ & \\
\hline $\begin{array}{l}\text { - Wound with a flat } \\
\text { adherent scar }\end{array}$ & $20 \%$ & $25 \%$ & \\
\hline $\begin{array}{l}\text { - Cutaneous retraction } \\
\text { without functional } \\
\text { affectation. }\end{array}$ & $8.6 \%$ & $7 \%$ & \\
\hline $\begin{array}{l}\text { - Cutaneous retraction } \\
\text { with functional } \\
\text { affectation }\end{array}$ & $5.7 \%$ & $8 \%$ & \\
\hline
\end{tabular}

Abbreviation: VAS, visual analogue scale.

cervical level in up to $3 \%$ of cases. A recent study published by Guillier et al compares the use of the Paul-André, or J incision, with the transverse incision, with the perception regarding the aesthetic result by the surgeon and patient satisfaction between both groups being the only statistically significant parameters, in both cases in favors of the transverse incision

Table 3 Type of cervical neck dissection performed and mean of isolated lymph nodes

\begin{tabular}{|l|l|l|l|l|}
\hline Type (Levels) & Transverse incision (\%) & Mean of node isolated & J or U Incision (\%) & Mean of node isolated \\
\hline JND (II-IV) & $49(71.3)$ & $18 \pm 7$ (Min: 11/Max: 39) & $55(78.57)$ & $16 \pm 5$ (Min: 6/Max: 29) \\
\hline SOHND (I-III) & $14(20.3)$ & $18 \pm 8$ (Min: 13/Max: 33) & $6(8.57)$ & $14 \pm 7$ (Min: 8/Max: 21) \\
\hline RMND (I-V) & $3(4.34)$ & $21 \pm 7$ (Min: 18/Max: 26) & $5(7.14)$ & $19 \pm 4$ (Min: 17/Max: 24) \\
\hline $\begin{array}{l}\text { Parotidectomy + ND } \\
\text { (II, III y V) }\end{array}$ & $3(4.34)$ & $17 \pm 3$ (Min: 16/Max: 22) & $4(5.71)$ & $15 \pm 5$ (Min: 13/Max: 19) \\
\hline Total & $69(100)$ & $18 \pm 7$ (Min:11/Max: 39) & $70(100)$ & $16 \pm 5$ (Min: 6/Max 29) \\
\hline
\end{tabular}

Abbreviations: JND, jugular neck dissection; RMND, radical modified neck dissection; SOHND, supraomohyoid neck dissection. 


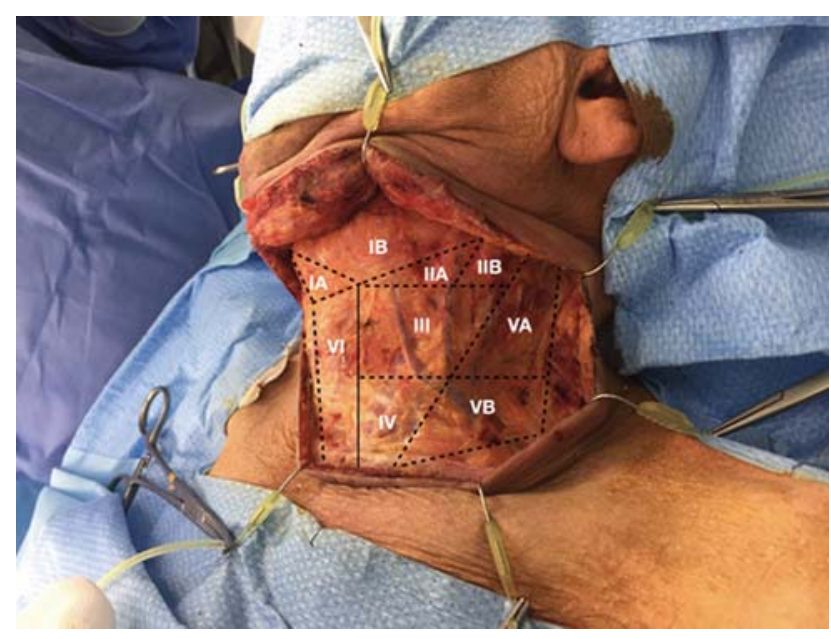

Fig. 2 Horizontal incision and exposure of all cervical levels. With preservation of the great auricular nerve.

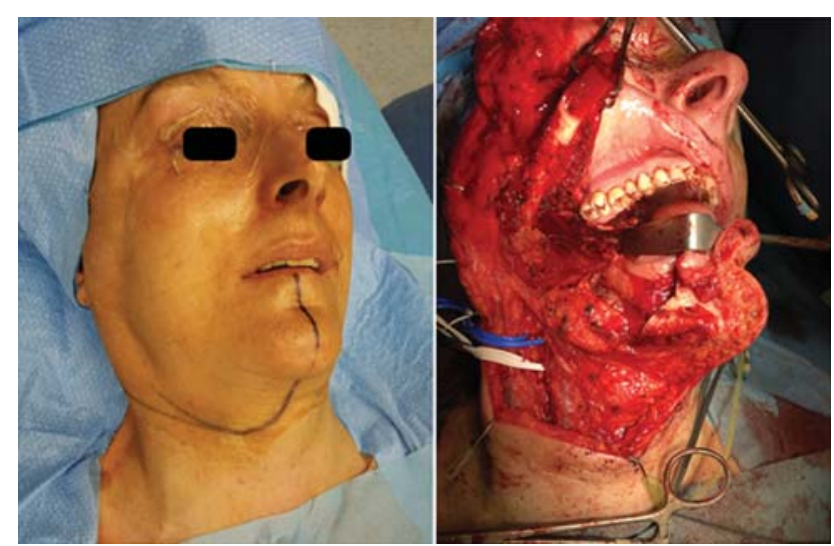

Fig. 3 Mandibular swing to approach a parapharyngeal space tumor.

group. ${ }^{21}$ In our study, we found significant results regarding aesthetic perception, but we could not find any difference according to the quality of life in patients. According to the surgeon's perception of the scar during the follow-up, correct healing was found in $65.7 \%$ of the patients in the study group and $60 \%$ of patients in the historical cohort.

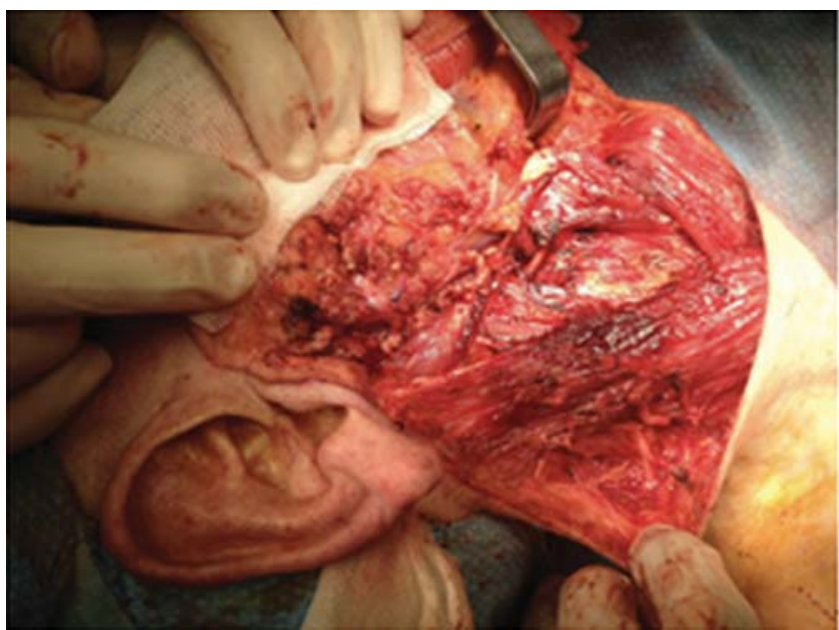

Concerning the extended transverse incision, since its original description, one of the main drawbacks has been the lack of exposure. However, in - Figs. 2, 3 and 4, we can see how with this incision we can correctly expose the totality of the cervical areas and even when we need to combine the cervical incision with other approaches for the primary lesion. In our series, although we found more N2-N3 patients in the control group, no statistical difference was found between both groups $(p=0.365)$; moreover, there was no need for the surgeon to limit lymph node resection due to inadequate field exposure in any of the cases. Additionally, the mean number of isolated lymph nodes per neck dissection, which was $18 \pm 7$ (min: 11/ max: 39), is in relation to the oncological parameters previously described. ${ }^{22}$ On the other hand, we must emphasize the importance of avoiding angles and their propensity to necrosis during flap elevation as well as a horizontal direction opposite to the large vessels,

In this way, this cervical incision guarantees a safe approach when the surgeon performs an oncological cervical procedure and, due that the direction of the incision is related to the natural lines of skin tension in the neck, the suture will have an adequate relaxation that will decrease the appearance of cicatricial retraction, guaranteeing an aesthetic benefit in patients subjected to a mutilating surgical procedure. (-Figs. $\mathbf{5}$ and $\mathbf{6}$ )

According to the complications rates associated with healing in this group of patients, only 4 (8.5\%) patients in the transverse incision group presented dehiscence of the operative wound, while $7(12.2 \%)$ in the historical group showed a dehiscence of the wound without finding differences between both groups $(p=0.078)$. The only factor related to the appearance of these complications in those patients was a body mass index lower than 18.5. Theoretically, the transverse incision could create scarring interfering with the lymphatic draining of the flap, especially compared with a J or hockey-stick incision, in our cohort 6 (12.7\%) patients developed superior flap lymphedema related to this problem, all of them resolved during the follow-up.

Furthermore, during the elevation of the flap using a transverse incision, the great auricular nerve (GAN) can be at risk, affecting the sensation at the level of the ear lobule.

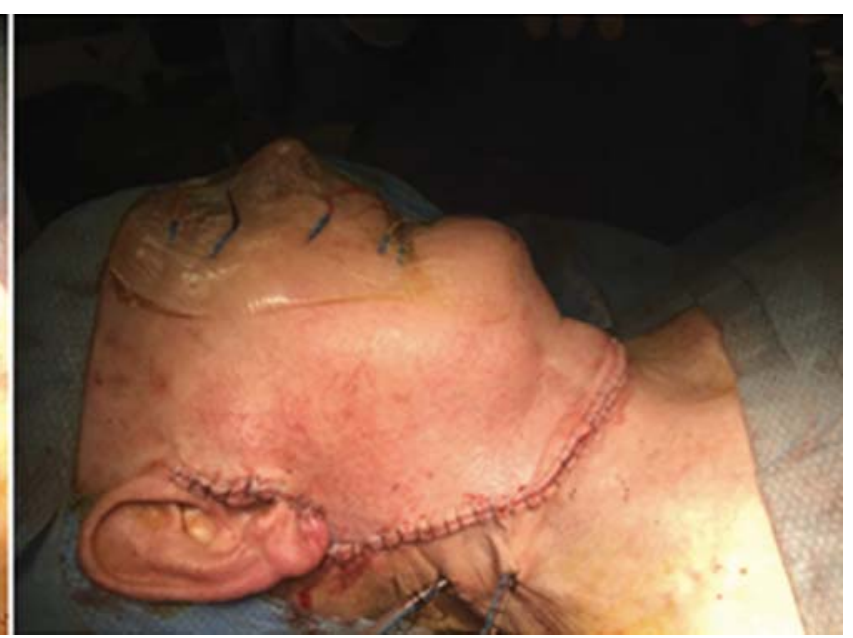

Fig. 4 Left superficial parotidectomy + carnival neck dissection. 


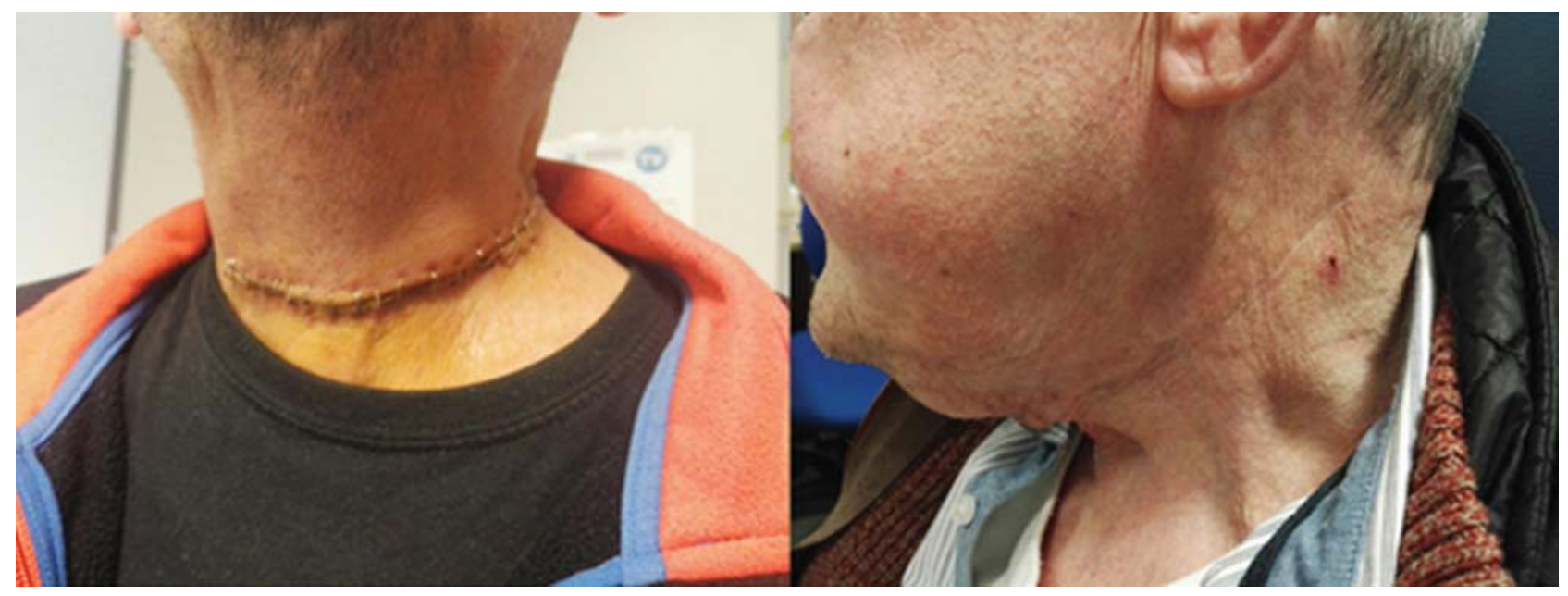

Fig. 5 Patient on his 6th postoperative day of left radical neck dissection (left). Patient after 1 month postoperatively due to selective jugular neck dissection - levels II-IV (right).

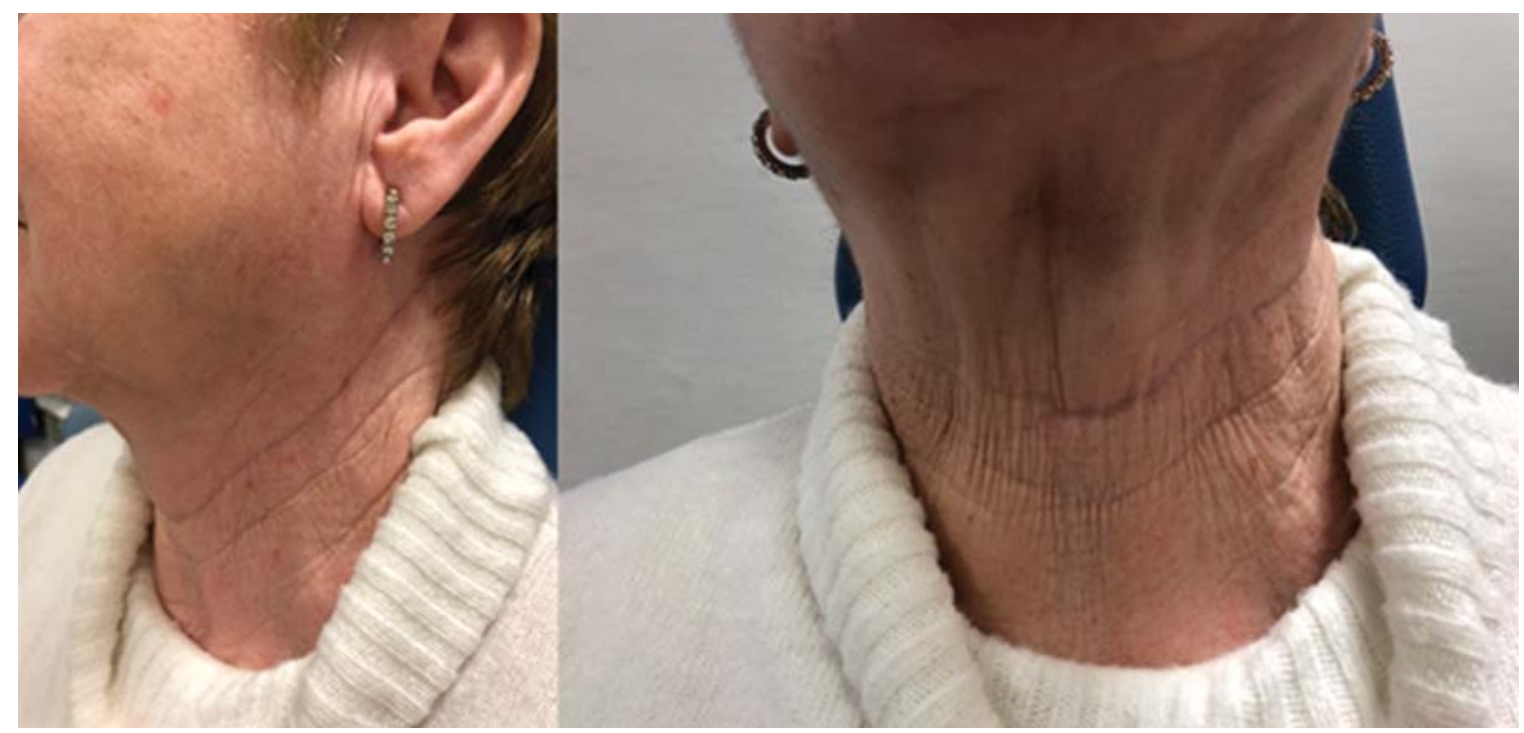

Fig. 6 Left supraomohyoid cervical neck dissection 6 months after surgery

Careful dissection is needed to avoid this kind of complication and even doing this, the risk still exists. In our cohort, 5 (10.6\%) patients suffered alteration of sensibility at the level of the auricle after the transverse incision, secondary to an injury during the flap elevation. However, due to the retrospective nature of data obtained from the historical cohort, we cannot evaluate the rate of lymphedema or GAN damage to compare and extract any conclusion. None of the patients presented hypertrophy scarring or keloid onset during follow-up.

Another important consideration is the use of regional free flaps during head \& neck surgery. In both cohorts, patients who precise the use of myomucosal pectoralis major flap for pharyngeal reinforcement after salvage total laryngectomy were included, in this patient, the bulky effect of the pedicle can be considered an aesthetic problem. However, no difference was found between the groups. Also, the use of fascio-cutaneous flaps like the supraclavicular artery island flap or radial forearm free flap for tongue reconstruction or pharyngeal wall reconstruction after total laryngectomy as well as one patient who precise a fibula free flap after a segmental mandibulectomy were included in the final analysis without any significant difference when compared with other patients. However, all those patients who needed a skin flap reconstruction after an ablative procedure of the head and neck were excluded.

Finally, we must highlight the limitations of the present study, which include the retrospective nature of the study, the absence of albumin level in both groups, the lack of a specific test to assess the quality of life of patients, the rate of patients affected by shoulder pain after neck dissection, and the difference in the proportion of patients having radiation prior to the neck surgery; with radiation being less frequent in the transverse incision group (13\%) when compared with the other incisions (25\%). 


\section{Conclusion}

The transverse incision represents a safe, aesthetic and oncological adequate option, associated with a lower cicatricial retraction rate, a lower rate of complications and allowing adequate exposure of the surgical field similar in comparison with the classic J or U incision.

Conflicts of Interest

The authors have no conflicts of interest to declare.

\section{References}

1 Crile GW. Excision of cáncer of the head and neck. With special reference to the plan of dissection base don 132 operations. JAMA 1906;47:1780-1786

2 Suarez O. El problema de las metástasis linfáticas y alejadas del cáncer de laringe e hipofaringe. Rev Bras Otorrinolaringol 1963; 23:83-99

3 Gavilán J, Moñoux A, Herranz J, Gavilán C. Functional neck dissection: Surgical technique. Oper Tech Otolaryngol-Head Neck Surg 1993; 4:258-265

4 Bocca E, Pignataro O, Sasaki CT. Functional neck dissection. A description of operative technique. Arch Otolaryngol 1980;106 (09):524-527

5 Robbins KT, Clayman G, Levine PA, et al; American Head and Neck Society; American Academy of Otolaryngology-Head and Neck Surgery. Neck dissection classification update: revisions proposed by the American Head and Neck Society and the American Academy of Otolaryngology-Head and Neck Surgery. Arch Otolaryngol Head Neck Surg 2002;128(07):751-758

6 Kocher Th. Extirpatio linguae. Deutsche Zeitschrift für Chir. 1880; 13: 146

7 Küttner H. Ueber die lymphgefásse und lymphdrüsen der Zunge mit beziehung auf die verbreitung des zungencarcinoms. Beitrage für Klinischen Chir. 1898;21:732

8 Martin H, Del Valle B, Ehrlich H, Cahan WG. Neck dissection. Cancer 1951;4(03):441-499
9 Macfee WF. Transverse incisions for neck dissection. Ann Surg 1960;151:279-284

10 Folz BJ, Silver CE, Rinaldo A, Ferlito A. Themistocles Gluck: biographic remarks emphasising his contributions to laryngectomy. Eur Arch Otorhinolaryngol 2011;268(08):1175-1179

11 Attie JN. A single transverse incision for radical neck dissection. Surgery 1957;41(03):498-502

12 Becker GD. The extended single transverse neck incision for composite resections. Surg Gynecol Obstet 1979;148(01):90-92

13 Kambic V, Sirca A. [Vascularization of the skin of the neck and its significance for the cutting method in radical neck dissection]. HNO 1967;15(02):46-49

14 Rabson JA, Hurwitz DJ, Futrell JW. The cutaneous blood supply of the neck: relevance to incision planning and surgical reconstruction. Br J Plast Surg 1985;38(02):208-219

15 On the anatomy and physiology of the skin. IV. The swelling capabilities of skin by Professor K. Langer presented at the meeting of 27th November 1861. Br J Plast Surg 1978;31(04):273-276

16 Chagas JF, Pascoal MB, Aquino JL, et al. Single transverse extended incision for radical neck dissection. Rev Col Bras Cir 2016;43(04): 270-275

17 Ellis M. Surgical techniques following irradiation of the neck. J Laryngol Otol 1963;77:872-908

18 Stell PM. Transverse incisions for radical neck dissection. Br J Surg 1969;56(04):286-288

19 Babcock WW Jr, Conley J. Neck incision in block dissection. Experiences with the long anterior cervical flap incision. Arch Otolaryngol 1966;84(05):554-557

20 Acar A, Dursun G, Aydin O, Akbaş Y. J incision in neck dissections. J Laryngol Otol 1998;112(01):55-60

21 Guillier D, Moris V, Al Hindi AA, et al. Surgical approaches in neck dissection: Comparing functional, oncologic and aesthetic aspects of transverse cervicotomy to Paul André's approach. Ann Chir Plast Esthet 2017;••• pii: S0294-1260(17)30122-X [ Epub ahead of print ] . Doi: 10.1016/j.anplas.2017.07.017

22 Robinson TJ, Thomas S, Dinan MA, Roman S, Sosa JA, Hyslop T. How Many Lymph Nodes Are Enough? Assessing the Adequacy of Lymph Node Yield for Papillary Thyroid Cancer. J Clin Oncol 2016; 34(28):3434-3439 